University of South Florida

DIGITAL COMMONS

Digital Commons @ University of

@ UNIVERSITY OF SOUTH FLORIDA

South Florida

\title{
The Interactive Effects of Antisocial Personality Disorder and Court-Mandated Status on Substance Abuse Treatment Dropout
}

\author{
Stacey B. Daughters \\ University of Maryland \\ Brooke A Stipelman \\ The National Cancer Institute \\ Marsha N. Sargeant \\ University of Southern California \\ Randi Schuster \\ University Of Illinois at Chicago \\ Marina Bornovalova \\ University of South Florida, bornovalova@usf.edu
}

See next page for additional authors

Follow this and additional works at: https://digitalcommons.usf.edu/psy_facpub

Part of the Psychology Commons

\section{Scholar Commons Citation}

Daughters, Stacey B.; Stipelman, Brooke A; Sargeant, Marsha N.; Schuster, Randi; Bornovalova, Marina; and Lejuez, C W, "The Interactive Effects of Antisocial Personality Disorder and Court-Mandated Status on Substance Abuse Treatment Dropout" (2008). Psychology Faculty Publications. 134.

https://digitalcommons.usf.edu/psy_facpub/134

This Article is brought to you for free and open access by the Psychology at Digital Commons @ University of South Florida. It has been accepted for inclusion in Psychology Faculty Publications by an authorized administrator of Digital Commons @ University of South Florida. For more information, please contact digitalcommons@usf.edu. 
Authors

Stacey B. Daughters, Brooke A Stipelman, Marsha N. Sargeant, Randi Schuster, Marina Bornovalova, and C W Lejuez 


\title{
The Interactive Effects of Antisocial Personality Disorder and Court-Mandated Status on Substance Abuse Treatment Dropout
}

\author{
Stacey B. Daughters, Ph.D., Brooke A. Stipelman, Marsha N. Sargeant, Randi Schuster, \\ Marina A. Bornovalova, and C.W. Lejuez, Ph.D. \\ Center for Addictions, Personality, and Emotion Research, University of Maryland
}

\begin{abstract}
The present study sought to examine the interactive effects of court-mandated (CM) treatment and antisocial personality disorder (ASPD) on treatment dropout among 236 inner-city male substance users receiving residential substance abuse treatment through a pretrial release to treatment program. Of the 236 participants, $39.4 \%(n=93)$ met criteria for ASPD and $72.5 \%(n=171)$ were mandated to treatment by the court system. Results indicated a significant interaction between ASPD and CM status, such that ASPD patients voluntarily receiving treatment were significantly more likely to drop out of treatment than each of the other groups. Subsequent discrete-time survival analyses to predict days until dropout using Cox proportional hazards regression indicated similar findings, with ASPD patients voluntarily receiving treatment completing fewer days of treatment than each of the other groups. These findings suggest the effectiveness of the court system in retaining ASPD patients, as well as the role of ASPD in predicting treatment dropout for individuals who are voluntarily in treatment. Implications are discussed including the potential value of early implementation of specialized interventions aimed at improving adherence for ASPD patients who are receiving treatment voluntarily.
\end{abstract}

\section{Keywords}

Substance Abuse Treatment; Antisocial Personality Disorder; Court Mandated; Treatment Dropout

\section{Introduction}

\begin{abstract}
Antisocial Personality Disorder (ASPD) is defined by the DSM-IV as a pervasive pattern of disregard for and violation of the rights of others, and is characterized by chronic deviant behavior, deceitfulness, and a lack of conscience (APA, 1994). Although ASPD is present in only about 3-4\% of the general population (Kessler et al., 1994), it is highly pervasive among individuals with a substance use disorder. Approximately $90 \%$ of individuals diagnosed with ASPD are concomitant substance abusers (Forrest, 1991), and rates of ASPD are upwards of 40-50\% in drug treatment samples (Brooner, King, Kidorf, Schmidt, \& Bigelow, 1997; Messina, Wish, \& Nemes, 1999). This dual diagnosis is especially problematic due to its association with a number of negative outcomes such as aggressive
\end{abstract}

(C) 2007 Elsevier Inc. All rights reserved.

Address Correspondence: Stacey B. Daughters, Ph.D., Center for Addictions, Personality, and Emotion Research, Department of Psychology, University of Maryland, College Park, MD 20742, Ph: 301.405.5760, sdaughters@ psyc.umd.edu.

Publisher's Disclaimer: This is a PDF file of an unedited manuscript that has been accepted for publication. As a service to our customers we are providing this early version of the manuscript. The manuscript will undergo copyediting, typesetting, and review of the resulting proof before it is published in its final citable form. Please note that during the production process errors may be discovered which could affect the content, and all legal disclaimers that apply to the journal pertain. 
and violent behavior (Brooner, Schmidt, Felch, \& Bigelow, 1992; Cottler, Price, Compton, \& Mager, 1995), serious criminal activity (e.g. use of a weapon, felony arrests; Abrams, 1989; Brooner et al., 1992; Cottler et al., 1995), elevated risk of contracting and transmitting HIV (Brooner, Greenfield, Schmidt, \& Bigelow, 1993; Compton, Cottler, Shillington, \& Price, 1995) and illicit drug use (Compton, Cottler, Jacobs, Ben-Abdallah, \& Spitznagel, 2003; King, Kidorf, Stoller, Carter \& Brooner, 2001).

Recent research has begun to focus on the ability of traditional substance use treatment settings to retain patients with both ASPD and substance dependence, as treatment length is one of the most consistent predictors of successful substance use outcomes (Gossop, Marsden, Stewart, \& Treacy, 2002; Martin et al., 2003; Simpson, Joe, \& Brown, 1997). There have been a number of studies suggesting that substance users with comorbid ASPD are at an increased risk for treatment dropout and subsequent return to drug use and criminal behavior (e.g. Alterman, Rutherford, Cacciola, McKay, \& Boardman, 1998; Cacciola, Rutherford, Alterman, McKay, \& Snider, 1996; Carroll, Ball, \& Rounsaville, 1993; Greenberg, Otero, \& Villanueva, 1994; Kokkevi, Stefanis, Anastasopoulou, \& Kostogianni, 1998; Leal, Ziedonis, \& Kosten, 1994). In particular, some have suggested that substance users with ASPD lack the intrinsic motivation necessary to remain in treatment long enough to achieve the full benefits (e.g., Condelli \& Hubbard, 1994). However, these finding have not been consistent, with a handful of other studies reporting either success in treating this population or no differences in retention rates for substance users with and without ASPD co-morbidity (e.g. Gil, Nolimal, \& Crowley, 1992; King et al., 2001; Marlowe, Kirby, Festinger, Husband, \& Platt, 1997). Therefore, it remains unclear the extent and circumstance under which ASPD is a risk factor for poor substance use treatment outcomes.

One variable that may be affecting treatment retention rates for ASPD patients is whether the patient is receiving treatment voluntarily or through the court system. As one example, individuals in pretrial release to treatment programs are offered the opportunity to avoid a criminal record or incarceration contingent upon the successful completion of a substance use treatment program (Young, Fluellen, \& Belenko, 2004). Overall, empirical evidence suggests that these programs are effective in retaining patients in treatment, reducing substance use, and reducing rates of recidivism compared to criminal offenders not mandated to court and those mandated to programs such as probation and drug court (Harrell \& Cavanaugh, 1995; Harrell, 1998; Young, 2002; Young \& Belenko, 2002; Young, Fluellen, \& Belenko, 2004). For instance, patients in a pretrial program in Brooklyn, NY, the Drug Treatment Alternative to Prison (DTAP) program, were compared to control offenders and patients mandated to treatment through parole, probation, and drug court programs. Findings indicated that the DTAP patients had higher rates of retention than the other groups at both 6 and 12 month post-admission follow-ups (Young, 2002; Young \& Belenko, 2002). Further, a follow-up study examining the effectiveness of DTAP reported that criminal recidivism among DTAP participants were substantially below those of a matched comparison group of offenders who were mandated to treatment from conventional criminal justice sources (Young, Fluellen, \& Belenko, 2004). In considering the effects of pretrial release to treatment programs on individuals with ASPD, one study examining treatment outcome in a group of court-mandated substance users found that comorbid ASPD was not associated with treatment dropout, and that this group fared equally well compared to the court mandated non-ASPD patients in terms of reduced drug use and recidivism rates (Messina, Wish, \& Nemes, 1999), suggesting the feasibility of court mandated programs in retaining substance abusing clients with ASPD in treatment.

Based on suggestive, yet mixed findings separately suggesting the potential relevance of ASPD status and the role of the court system in understanding substance use treatment dropout, further research considering the interaction of these variables may be useful. 
Specifically, given the knowledge that ASPD patients are at an increased risk for treatment dropout, and that utilizing the court system to retain substance using patients appears effective, it is important to understand whether the court system improves retention rates specific to ASPD patients. Evidence from the Messina, Wish, and Nemes (1999) study suggests that ASPD patients respond well to court-mandated treatment. However, a voluntary-treatment comparison group was not included in the study. This omission is important because it precludes comparison with ASPD drug users receiving treatment on a voluntary basis, who may be at a heightened risk for treatment dropout in the absence of treatments with clear contingencies for remaining in treatment (Brooner, Kidorf, King, \& Stoller, 1998; Messina, Farabee, \& Rawson, 2003; Silverman et al., 1998). Thus, the current study attempts to further address this issue by examining the interactive effects of courtmandated treatment and ASPD status on treatment dropout among 236 inner-city male substance users receiving residential substance abuse treatment through a pretrial release to treatment program.

\section{Materials and Method}

\section{Participants}

Participants for this study included 236 male residents of the Salvation Army Harbor Light residential substance abuse treatment facility in Northeast Washington, DC. The mean age of the sample was 40.5 years $(S D=9.8), 91.7 \%$ were African American, and $50.7 \%$ reported earning an income of less than $\$ 20 \mathrm{~K}$ per year. For the current sample, patients entered the treatment center either voluntary or under a pretrial release to treatment program through the District of Columbia Pretrial Services Agency. In this program, drug offenders who were awaiting trial were granted pretrial supervision through the pretrial services offered through the court system. Under this status, individuals were given the option to receive substance abuse treatment as a way to ensure appearance in court, provide community safety, and address the underlying cause of recidivism. The patients were aware that if they successfully completed the program within a designated time frame they were given the opportunity to have their sentences reduced or expunged. However, in cases where they voluntarily withdrew from the program or were noncompliant with the terms of their release contract, they would be subject to a variety of sanctions including contempt of court and detention or revocation of their release.

Patients were contracted to a specific length of stay upon entry into the treatment center. For the current sample, contract lengths included 30 days (42.2\%), 60 days (21.5\%), 90 days $(11.0 \%)$ or 180 days (25.3\%). Pretrial release to treatment patients were assigned contract lengths based on an assessment of the patients' need from the Social Services and Assessment Center of the D.C. Pretrial Services Agency. Although there are no clear criteria for assignment to a specific contract length, the recommendation takes into consideration the patients' drug use and criminal history. Voluntary patients are assigned contract lengths based upon the availability of financial support from government and community agencies.

Treatment at Harbor Light consisted primarily of group sessions focused on a combination of relapse prevention, AA/NA, chemical dependency, and functional analysis. While in treatment, patients were required to abstain from all drug use, with the exception of nicotine, as well as remain on the center grounds for the duration of their stay. Detoxification was required prior to entrance into the treatment facility and regular drug testing was provided, with positive tests serving as grounds for immediate dismissal from the center.

\section{Procedure}

Adult male residents were approached within their first week of treatment and were asked if they would be interested in participating in a research study examining personality and 
behavioral characteristics of substance users. Interested participants were given a more detailed verbal description of the study and then provided written informed consent; all aspects of the study and the consent forms were approved by the University of Maryland Institutional Review Board.

Following informed consent, participants completed the Antisocial Personality Disorder Module of the Structured Clinical Interview for DSM-IV Personality Disorders (SCID-II; First, Spitzer, Gibbon, Williams \& Benjamin, 1997) and the Substance Dependence Modules of the Structured Clinical Interview for DSM-IV Axis I Disorders (SCID-I; First, Spitzer, Gibbon \& Williams, 2002). Participants also completed self-report measures including a demographics form, the Center for Epidemiological Studies-Depression scale (CES-D; Radloff, 1977) to assess depressive affect and overall depressive symptomatology in the week prior to testing, and polysubstance use. Polysubstance use was assessed using a self report measure of frequency of substance use across the 10 drug categories in line with the work of Kirisci, Vanyukov, Dunn, and Tarter (2002). Participants indicated their use for each substance across the following categories: never, one time, monthly, 2-4 times a month, 2-3 times a week, or 4 or more times a week in the past year. Polysubstance use was defined as using 3 or more substance on a weekly basis in the past year. We chose 3 substances because (1) in the DSM-IV-TR polysubstance dependence requires an individual to use at least three different substances in the same 12-month period to be given the diagnosis of polysubstance dependence (APA, 1994), and (2) $88.3 \%$ of the sample reported using at least 2 substances on a weekly basis in the past year, thereby precluding an analysis of any meaningful differences. Participants also provided additional information on their past treatment history including how many previous substance abuse treatment attempts they had made prior coming to Harbor Light.

The entire assessment lasted approximately 1 hour. Patients received $\$ 15$ in cash for participation in the study. This payment was deposited into their account at Harbor Light, which they received upon discharge from the residential treatment center.

\section{Analytic Plan}

Analyses were conducted with dropout as the primary dependent variable. Given the multiple contract lengths, we decided to examine dropout by 30 days of treatment for three reasons: 1) this was the minimum contract duration across all participants, 2) it is consistent with our previous research on treatment dropout with multiple contract durations (e.g., Daughters et al., 2005); and 3) 30 day contracts are considerably more common here as well as outside of this Center, thereby increasing the generalizability of the findings ${ }^{1}$. Because of the skewed distribution in dropout at 30 days of treatment (13.1\% dropped out of treatment), this variable was coded categorically as dropout or completer across 30 days of treatment. In addition to our primary analyses with the categorical variable of dropout, we also conducted a discrete-time survival analysis to predict days until dropout during the first 30 days of treatment using Cox proportional hazards regression to provide a richer analysis of dropout that does not require normally distributed outcome data.

Primary analyses began with descriptives for the entire sample across the dependent variable of dropout, the independent variables of ASPD and court-mandated (CM) status, and the potential covariates which include demographics, contract length, depressive symptoms, polysubstance use, treatment history, and substance dependence. Next, we examined differences in the potential covariates across the dependent variable and then the

\footnotetext{
${ }^{1}$ We also conducted all analyses with 'Overall Dropout' as the dependent variable (if a patient dropped out at any time in their contract) and our analyses remained unchanged.
} 
independent variables to determine their use as covariates in subsequent regression analyses. The primary analyses began with a logistic regression to examine the categorical variable of dropout, utilizing covariates, ASPD status and CM status in the first step, and the interaction of ASPD and CM in the second step. Follow-up chi-square analyses were used to compare dropout across each resulting group based on a significant interaction. Secondary analyses used methodologies from survival analysis (e.g., Kaplan-Meier, Cox regression) to model the time to 30-day dropout, with days as the time scale.

\section{Results}

\section{Descriptives for the Entire Sample}

In the final sample, $13.1 \%$ dropped out of treatment within 30 days (dropouts; $n=31$ ) and $86.9 \%$ completed at least 30 days of treatment (completers, $n=205$ ); $39.4 \%$ met criteria for DSM-IV antisocial personality disorder (ASPD; $n=93$ ); and $72.5 \%$ were court mandated to treatment $(\mathrm{CM} ; n=171)$. Table 1 provides a comparison of 30-day treatment dropout and overall treatment dropout (participants who dropped out at any time during treatment) between $\mathrm{CM}$ and voluntary patients within each contract length. The mean score on the CES-D for the entire sample was $22.3(S D=11.4)$. With regard to substance use, $58.4 \%$ of the sample reported polysubstance use, $33.1 \%(n=78)$ met criteria for alcohol dependence, $14.0 \%(n=33)$ for marijuana dependence, $38.6 \%(n=91)$ for heroin dependence, $58.1 \%(n$ $=137)$ for cocaine dependence, $5.9 \%(n=14)$ for hallucinogen dependence, and $27.2 \%(n=$ 63 ) of the sample met dependence for more than one substance.

\section{Relationship among Covariates and Dropout Status}

Analyses of the relationship comparing dropout status and potential covariates are provided in Table 2. Significantly more dropouts than completers met criteria for marijuana dependence, $\chi^{2}(1)=6.72, p<.01$. There were no significant differences between dropouts and completers on dependence on any other substance, polysubstance use, contract length, age, income, or self-reported depressive symptoms ( $p$ s > .05).

\section{Relationship among Covariates, ASPD, and Court Mandated Status}

Differences in contract length comparing voluntary and court-mandated patients can be found in Table 3. As there were no significant differences in contract length within ASPD patients, the data for only the voluntary and court-mandated groups are presented in Table 3 . The CM patients were significantly more likely to have 30 day $\left[\chi^{2}(1)=35.8, p<.001\right]$ and 60 -day $\left[\chi^{2}(1)=15.3, p<.001\right]$ contracts and the voluntary patients were more likely to have 180 day contracts $\left[\chi^{2}(1)=97.3, p<.001\right]$.

Considering ASPD and CM status together, the relationship between the four resulting groups and the covariates are discussed below and presented in Table 4 . Significantly more of the Voluntary/No ASPD than CM/No ASPD patients met criteria for heroin dependence $\left[\chi^{2}(1)=4.8, p<.05\right]$. Voluntary/No ASPD patients were also significantly more likely than CM/ASPD patients to be a polysubstance user $\left[\chi^{2}(1)=5.4, p<.05\right]$ and meet criteria for heroin dependence $\left[\chi^{2}(1)=7.6, p<.01\right]$. The Voluntary/ASPD patients were significantly more likely than the CM/No ASPD patients to meet criteria for alcohol $\left[\chi^{2}(1)=9.6, p<\right.$. $01]$ and marijuana $\left[\chi^{2}(1)=7.6, p<.01\right]$ dependence. Finally, the Voluntary/ASPD patients were significantly more likely than the CM/ASPD patients to report a lower income $\left[\chi^{2}(1)\right.$ $=4.3, p<.05]$ and meet criteria for alcohol dependence $\left[\chi^{2}(1)=5.0, p<.05\right]$. There were no group differences in cocaine dependence, hallucinogen dependence, age, or self-reported depressive symptoms. 


\section{Predictors of Treatment Dropout}

A logistic regression analysis was conducted to determine the unique and interactive effects of ASPD and CM status on 30-day treatment dropout. As indicated in Table 5, CM status and ASPD were included in the first step, along with variables that demonstrated a significant group difference, namely contract duration, income, alcohol dependence, heroin dependence, marijuana dependence, and polysubstance use. In the first step there was a main effect for CM status, indicating that individuals who were court-mandated to treatment were significantly more likely to drop out of treatment than those who were not court-mandated (Wald $=7.41, p<.01 ; \mathrm{OR}=0.21 ; 95 \% \mathrm{CI}=0.07-0.65$ ). The ASPD $/ \mathrm{CM}$ status interaction variable was entered in a second step, and the final model was significant, $\chi^{2}=26.2, p<$. 001, with the ASPD/CM status interaction significantly related to treatment dropout, (Wald $=8.48, p<.01, \mathrm{OR}=0.04,95 \% \mathrm{CI}=0.01-0.36$ ). Follow-up chi square analyses indicated that Voluntary/ASPD patients were significantly more likely to drop out of treatment than Voluntary/non ASPD $\left(\chi^{2}(1)=4.4, p<.05\right)$, Court Mandated/ASPD $\left(\chi^{2}(1)=4.1, p<.001\right)$, and $\mathrm{CM} /$ non ASPD $\left(\chi^{2}(1)=10.1, p<.001\right)$ patients. There were no differences in rates of treatment dropout across Voluntary/non ASPD, CM/ASPD, and CM/non ASPD patients.

As a richer analysis of dropout, we also conducted a discrete-time survival analysis to predict days until dropout during the first 30 days of treatment using Cox proportional hazards regression. Court-mandated status and ASPD were included in the first step, along with variables that demonstrated a significant group difference, namely contract duration, income, alcohol dependence, heroin dependence, marijuana dependence, and polysubstance use. The ASPD/CM status interaction variable was entered in a second step, and the final model was significant, $\chi^{2}(9, N=236)=36.2, p<.001$, with the ASPD/CM status interaction significantly related to treatment dropout, $B=-3.17, S E=1.11$, hazard ratio $=$. $04, p<.01$. We ran an additional Cox proportional hazards regression with the same variables but included all four groups, contrasting ASPD/voluntary status to the other 3 groups. As displayed in Figure 1, ASPD patients who enter treatment voluntarily were at an increased risk for dropping out of treatment compared to the other three groups.

\section{Discussion}

The current study examined the interactive effect of ASPD and court-mandated status on treatment dropout among substance users receiving residential treatment. Consistent with prior research (Glass \& Marlowe, 1994; Martin et al., 2003; Schnoll, Goldstein, Antes, \& Rinella, 1980), evidence indicated that court-mandated substance users were significantly more likely to remain in treatment compared to those voluntarily receiving treatment. Although there was no significant differences in treatment dropout between the ASPD and non-ASPD substance users, an interaction was evident such that dropout was more likely among ASPD patients voluntarily receiving treatment than ASPD patients who were courtmandated to treatment, suggesting that patients with comorbid ASPD and substance dependence who are not court-mandated to treatment are at an increased risk of dropping out of residential substance use treatment. The implications of these findings are twofold. First, the data support the utility of pretrial release to treatment programs in retaining ASPD substance users in the criminal justice system. Second, these findings suggest value in developing specialized interventions to be combined with standard treatment that meet the specific needs of ASPD substance users who enter treatment voluntarily to prevent premature treatment dropout.

Given these findings, an important question to answer is why ASPD and voluntary treatment entry indicates such a substantial vulnerability to treatment dropout. To this end, key characteristics of individuals with ASPD include the engagement in impulsive and chaotic behaviors and an inability to inhibit emotional responses, tolerate frustration and boredom, 
and problem solve (DSM-IV; APA, 1994). These vulnerabilities may place ASPD patients at a disadvantage in treatment such that abstinence is associated with withdrawal symptoms and social and environmental changes which often lead to increases in negative affective states such as frustration and irritability. Indeed, data suggests that ASPD substance users exhibit significantly lower levels of distress tolerance, or persistence in goal directed activity during times of emotional distress, than substance users without ASPD (Daughters, Sargeant, Bornovalova, Gratz, \& Lejuez, under review), and evidence indicates that low distress tolerance is significantly related to treatment dropout (Daughters et al., 2005). Thus, assessing this vulnerability in the beginning of treatment and subsequently providing appropriate interventions (i.e., distress tolerance skills) may serve to decrease rates of treatment dropout for this at-risk group.

An additional question resulting from these results is why court-mandated treatment facilitates treatment retention among individuals with ASPD. Current evidence suggests that substance users with ASPD respond particularly well to treatment programs that offer reinforcement contingencies (Brooner et al., 1998; Messina, Farabee, \& Rawson, 2003; Silverman et al., 1998). For example, Messina and colleagues (2003) randomly assigned a group of methadone maintained cocaine users with and without ASPD to one of four treatment conditions including cognitive-behavioral therapy (CBT), contingency management $(\mathrm{CM})$, cognitive-behavioral therapy plus contingency management $(\mathrm{CBT}+$ $\mathrm{CM}$ ), or methadone maintenance (MM). ASPD patients in the CM condition were significantly more likely to abstain from cocaine use than those in the CBT-only condition. Furthermore, ASPD patients in the CM condition were significantly more likely to abstain from cocaine use than non-ASPD patients in the CM condition, even after controlling for pre-existing differences, highlighting the specificity of the effects of CM interventions on individuals with ASPD. These results are consistent with the hypothesis that although individuals with ASPD may not be intrinsically motivated for substance use rehabilitation they are likely to comply when concurrently receiving a personal benefit or gain (Evans \& Sullivan, 1990; Valliant, 1975), even in the case of court-mandated treatment where the reinforcement contingencies are better characterized as negative reinforcement (avoidance of sever legal consequences) as opposed to positive reinforcement.

A number of limitations need to be considered when interpreting these results. First, our participants were mandated to treatment through a pretrial release to treatment program. There are a variety of additional court mandated programs, including drug court and probation, which need empirical attention prior to generalizing our findings to these groups. Second, this sample was limited to individuals receiving residential substance use treatment. Future studies need to determine if these results generalize across other types of treatment settings (e.g., outpatient). Third, other potential predictors of substance use treatment dropout such as social support, treatment readiness, self efficacy, and Axis-I comorbidity were not assessed. A more comprehensive assessment of psychopathology and other relevant drop-out predictors is warranted. For example, in addition to more standardized measures of treatment readiness or motivation, it will be important to assess factors that may influence ones feeling of commitment or obligation to treatment (i.e., social/family pressure). Fourth, the sample does not include women and primarily consists of low-income inner-city African Americans. Therefore, it is unclear if these findings would extend to females and individuals of other ethnicities and socioeconomic status. Finally, we did not conduct a comprehensive assessment of legal and criminal history, which evidence indicates may affect treatment retention (Nielson \& Scarpitti, 2002), highlighting the importance of including this variable in future studies.

In summary, the high prevalence rate of comorbid ASPD and substance dependence along with the large public health costs associated with this dual diagnosis has lead researchers to 
examine the ability of standard substance use interventions to effectively treat this population. Given the importance of treatment retention in long term substance use outcomes, the current study examined the interactive effect of ASPD and court-mandated status in predicting treatment dropout among a group of inner-city male substance users in a residential drug treatment facility. Along with highlighting the effectiveness of courtmandated treatment efforts in retaining ASPD substance users, these results suggest that substance dependent individuals with ASPD who are voluntarily in treatment are at an increased risk for treatment dropout compared to all other groups. Although the implications must be tempered by the limitations outlined above, this current paper sets the stage for future work to replicate these findings and extend them to consider exactly "why" individuals with ASPD are more likely to drop out of treatment when a legal obligation is not present and how to best address these vulnerabilities in treatment. The public health relevance of such knowledge would be further increased by the opportunity to develop specialized interventions aimed at these specific vulnerabilities and to implement these interventions in the early stages of substance use treatment with the goal of improving adherence for this at-risk group.

\section{Acknowledgments}

This work was supported by National Institute of Drug Abuse Grant DA018387 awarded to the first author. The authors thank Walter Askew, Pinque Alston, and Michelle Williams of the Salvation Army Harbor Light Residential Treatment Center of Washington, DC, for assistance in subject recruitment.

\section{References}

Abrams KM. The effect of co-occurring disorders on criminal career: Interaction of antisocial personality disorder, alcoholism, and drug disorders. International Journal of Law and Psychiatry. 1989; 12:133-148. [PubMed: 2599747]

Alterman AI, Rutherford MJ, Cacciola JS, McKay JR, Boardman CR. Prediction of 7 months methadone maintenance treatment response by four measures of antisociality. Drug and Alcohol Dependence. 1998; 49:217-223. [PubMed: 9571386]

American Psychiatric Association. Diagnostic and Statistical Manual of Mental Disorders. 4th. American Psychiatric Association; Washington, DC: 1994.

Brooner RK, Greenfield L, Schmidt CW, Bigelow GE. Antisocial personality disorder and HIV infection among intravenous drug abusers. American Journal of Psychiatry. 1993; 150:53-58. [PubMed: 8417580]

Brooner RK, Kidorf M, King VL, Stoller K. Preliminary evidence of good treatment response in antisocial drug abusers. Drug and Alcohol Dependence. 1998; 49:249-260. [PubMed: 9571389]

Brooner RK, King VL, Kidorf M, Schmidt CW, Bigelow GE. Psychiatric substance use comorbidity among treatment seeking opioid abusers. Archives of General Psychiatry. 1997; 54:71-80. [PubMed: 9006403]

Brooner RK, Schmidt CW, Felch LJ, Bigelow GE. Antisocial behavior of intravenous drug abusers: implications for a diagnosis of antisocial personality disorder: Increased HIV risk behavior. American Journal of Psychiatry. 1992; 149:482-487. [PubMed: 1554033]

Cacciola JS, Rutherford MJ, Alterman AI, McKay JR, Snider EC. Personality disorders and treatment outcome in methadone maintenance patients. Journal of Nervous and Mental Disease. 1996; 184:234-239. [PubMed: 8604033]

Carroll KM, Ball SA, Rounsaville BJ. A comparison of alternate systems for diagnosing antisocial personality disorder in cocaine abusers. Journal of Nervous and Mental Disease. 1993; 181:436443. [PubMed: 8320546]

Compton WM, Cottler LB, Shillington AM, Price RK. Is antisocial personality disorder associated with increased HIV risk behaviors in cocaine users? Drug and Alcohol Dependence. 1995; 37:3744. [PubMed: 7882872] 
Compton WM, Cottler LB, Jacobs JL, Ben-Abdallah A, Spitznagel EL. The role of psychiatric disorders in predicting drug dependence treatment outcomes. American Journal of Psychiatry. 2003; 160:890-895. [PubMed: 12727692]

Condelli WS, Hubbard RL. Relationship between time spent in treatment and client outcomes from therapeutic communities. Journal of Substance Abuse Treatment. 1994; 11:25-33. [PubMed: 8201630]

Cottler LB, Price RK, Compton WM, Mager DE. Subtypes of adult antisocial behavior among drug users. Journal of Nervous and Mental Disease. 1995; 183:154-161. [PubMed: 7891061]

Daughters SB, Lejuez CW, Bornovalova MA, Kahler C, Strong D, Brown R. Distress tolerance as a predictor of early treatment dropout in a residential substance abuse treatment facility. Journal of Abnormal Psychology. 2005; 114:729-734. [PubMed: 16351393]

Daughters SB, Sargeant M, Bornovalova MA, Gratz KL, Lejuez CW. The relationship between distress tolerance and antisocial personality disorder among male residential treatment seeking inner-city substance users. Behavior Research and Therapy. under review.

De Leon G. Legal pressure in therapeutic communities. Journal of Drug Issues. 1988; 18:625-640.

Evans, K.; Sullivan, J. Dual diagnoses: Counseling mentally ill substance abusers. New York: Guilford Press; 1990.

First, MB.; Spitzer, RL.; Gibbon, M.; Williams, JBW. Structured Clinical Interview for DSM-IV-TR Axis I Disorders, Research Version, Non-Patient Edition (SCID-I/NP). New York: Biometrics Research, New York State Psychiatric Institute; 2002.

First, MB.; Spitzer, RL.; Gibbon, M.; Williams, JBW.; Benjamin, L. Structured Clinical Interview for DSM-IV Personality Disorders (SCID-II). Washington DC: American Psychiatric Publishing, Inc; 1997.

Forrest, GG. Chemical Dependency and Antisocial Personality Disorder: Psychotherapy and Assessment Strategies. New York: Hawthorne Press; 1991.

Gil K, Nolimal D, Crowley TJ. Antisocial personality disorder, HIV risk behavior and retention in methadone maintenance therapy. Drug and Alcohol Dependence. 1992; 30:247-252. [PubMed: 1396106]

Glass, DJ.; Marlowe, DB. Comparing state agency mandated and voluntary outpatients treatment outcome and retention in a cocaine addiction program; Paper presented at the 1994 Biennial Conference of the American Psychology-Law Society; Santa Fe, New Mexico. 1994.

Gossop M, Marsden J, Stewart D, Treacy S. Change and stability of change after treatment of drug misuse 2-year outcome from the National Treatment Outcome Research Study (UK). Addictive Behaviors. 2002; 27:155-166. [PubMed: 11817759]

Greenberg W, Otero J, Villanueva L. Irregular discharges from a dual diagnosis unit. American Journal of Drug and Alcohol Abuse. 1994; 20:355-371. [PubMed: 7977220]

Harrell, A. Drug courts and the role of graduated sanctions National Institute of Justice research preview. Government Printing Office; Washington, DC: 1998. 1998

Harrell, A.; Cavanaugh, S. Compliance with drug abstinence requirements during pretrial release: a comparison of graduated sanctions and treatment for drug felony defendants; Paper presented at the 47th Annual Meeting of the American Society of Criminology; Boston, MA. 1995.

Kaplan EL, Meier P. Nonparametric estimation from incomplete observations. Journal of the American Statistical Association. 1958; 53:457-481.

Kessler RC, McGonagle KA, Zhao S, Nelson CB, Hughes M, Eshleman S, Wittchen HU, Kendler KS. Lifetime and 12-month prevalence of DSM-III-R psychiatric disorders in the United States. Results from the National Comorbidity Survey. Archives of General Psychiatry. 1994; 51:8-19. [PubMed: 8279933]

King VL, Kidorf MS, Stoller KB, Carter JA, Brooner R. Influence of antisocial personality subtype on drug abuse treatment response. Journal of Nervous and Mental Disease. 2001; 189:593-601. [PubMed: 11580002]

Kirisci L, Vanyukov M, Dunn M, Tarter R. Item response theory modeling of substance use: An index based on 10 drug categories. Psychology of Addictive Behaviors. 2002; 16:290-298. [PubMed: 12503901] 
Kokkevi A, Stefanis N, Anastasopoulous E, Kostogianni C. Personality disorders in drug abusers: Prevalence and their association with axis I disorders as predictors of treatment retention. Additive Behaviors. 1998; 23:841-853.

Langan, PA.; Cunniff, MA. Recidivism of felons on probation, 1986-89. Washington, DC: U.S. Department of Justice; 1992.

Leal J, Ziedonis D, Kosten T. Antisocial personality disorder as a prognostic factor for pharmacotherapy of cocaine dependence. Drug and Alcohol Dependence. 1994; 35:31-35. [PubMed: 8082553]

Marlowe DB, Kirby KC, Festinger DS, Husband SD, Platt JJ. Impact of comorbid personality disorders and personality disorder symptoms on outcomes of behavioral treatment for cocaine dependence. Journal of Nervous and Mental Disease. 1997; 185:483-490. [PubMed: 9284861]

Martin B, Clapp L, Bialkowski D, Bridgeford D, Amponsah A, Lyons L, Beresford T. Compliance to supervised disulfiram therapy: A comparison of voluntary and court-ordered patients. The American Journal on Addictions. 2003; 12:137-143. [PubMed: 12746088]

Messina N, Farabee D, Rawson R. Treatment responsivity of cocaine-dependent patients with antisocial personality disorder to cognitive-behavioral and contingency management interventions. Journal of Consulting and Clinical Psychology. 2003; 71:320-329. [PubMed: 12699026]

Messina N, Wish ED, Nemes S. Therapeutic community treatment for substance abusers with antisocial personality disorder. Journal of Substance Abuse Treatment. 1999; 17:121-128. [PubMed: 10435260]

Nielson AL, Scarpitti FR. Predicting retention in a therapeutic community for incarcerated substance abusers. Journal of Offender Rehabilitation. 2002; 34(3):47-65.

Nurco DN, Hanlon TE, Kinlock TW. Recent research on the relationship between illicit drug use and crime. Behavioral Sciences and the Law. 1991; 9:221-249.

Radloff LS. The CES-D scale: A self-report depression scale for research in the general population. Applied Psychological Measurement. 1977; 1:385-401.

Satel, S. Drug treatment: The case for coercion. Washington, DC: American Enterprise Institute press; 1999.

Schnoll SH, Goldstein MR, Antes DE, Rinella VJ. The impact of legal involvement on substance abusers in a residential treatment setting. Corrective and Social Psychology. 1980; 26:21-28.

Silverman K, Wong C, Umbricht-Schneiter A, Montoya I, Schuster C, Preston K. Broad beneficial effects of cocaine abstinence reinforcement among methadone patients. Journal of Consulting and Clinical Psychology. 1998; 66:811-824. [PubMed: 9803700]

Simpson DD, Joe GW, Brown BS. Treatment retention and follow-up outcomes in the drug abuse treatment outcome study (DATOS). Psychology of Addictive Behaviors. 1997; 11:294-307.

Valliant G. Sociopathy as a human process: A viewpoint. Archives of General Psychiatry. 1975; 32:178-283. [PubMed: 1115566]

Young D. Impacts of perceived legal pressure on retention in drug treatment. Criminal Justice and Behavior. 2002; 29:27-55.

Young D, Belenko S. Program retention and perceived coercion in three models of mandatory drug treatment. Journal of Drug Issues. 2002; 32:297-328.

Young D, Fluellen R, Belenko S. Criminal recidivism in three models of mandatory drug treatment. Journal of Substance Abuse Treatment. 2004; 27:313-323. [PubMed: 15610833] 


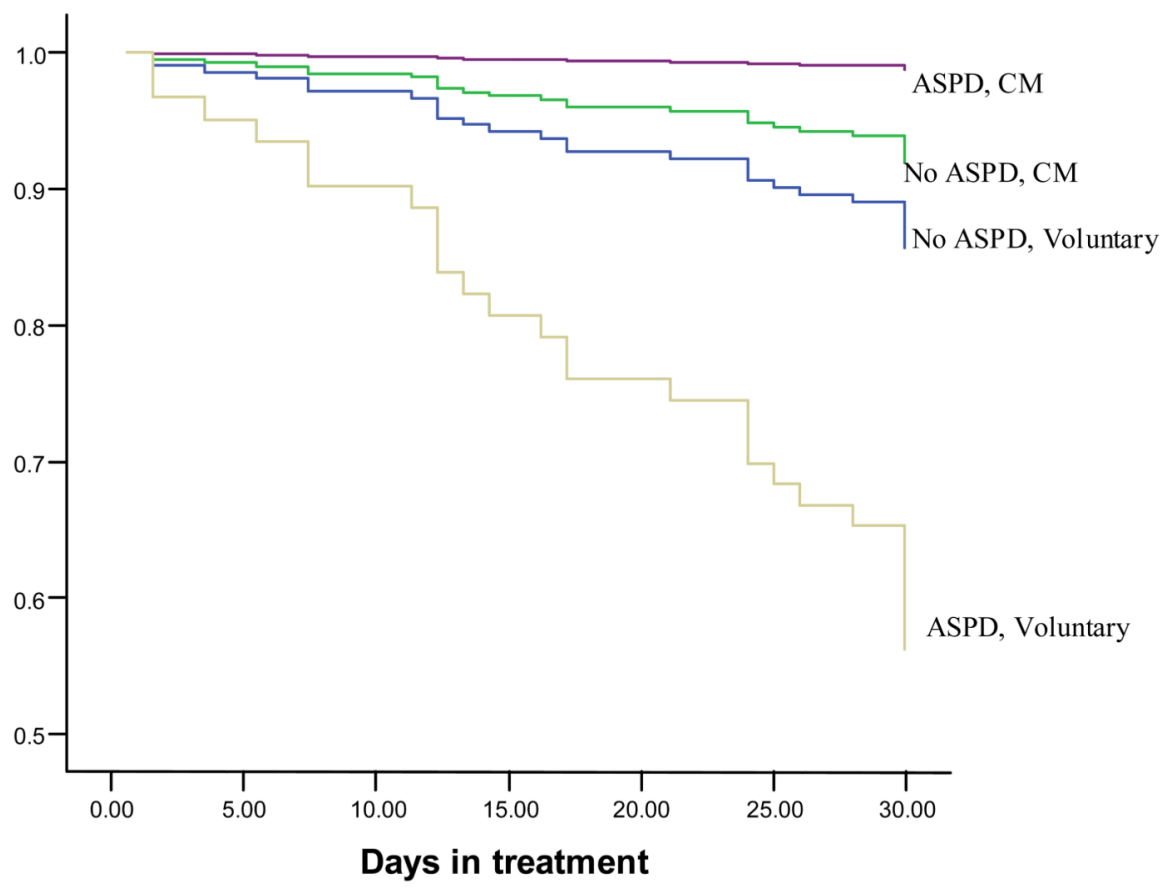

Figure 1.

Group differences in cumulative survival to dropout (Y-axis) over the first 30 days of treatment among antisocial personality disorder (ASPD) and non-ASPD patients who are either court mandated (CM) to treatment or enter treatment voluntarily. 


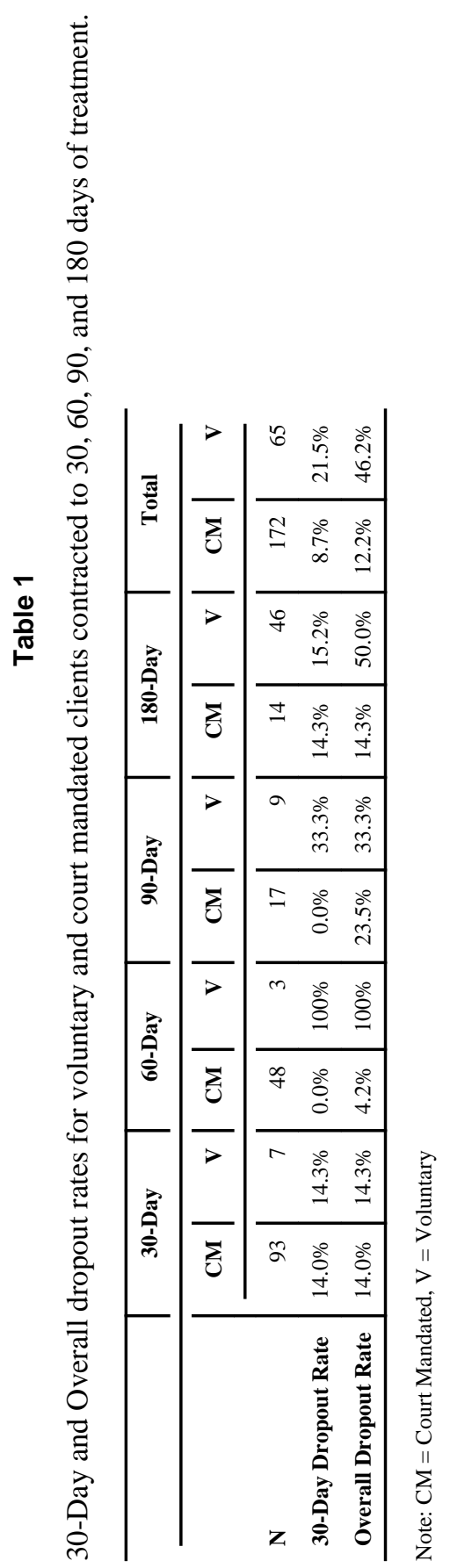


Table 2

Differences between dropouts and completers on demographics, substance dependence, and self report measures.

\begin{tabular}{l|c|c}
\hline & Dropouts $(\boldsymbol{n}=\mathbf{3 1})$ & Completers $(\boldsymbol{n = 2 0 5})$ \\
\hline Age & $38.8(\mathrm{SD}=9.7)$ & $41.2(\mathrm{SD}=9.7)$ \\
Income (> 20k) & $62.1 \%$ & $50.0 \%$ \\
\# of Previous Treatments & $2.69(S D=3.50)$ & $2.12(S D=1.82)$ \\
Depressive Symptoms & $22.7(\mathrm{SD}=11.7)$ & $22.2(\mathrm{SD}=11.4)$ \\
Alcohol Dependence & $44.8 \%$ & $31.4 \%$ \\
Cocaine Dependence & $62.1 \%$ & $57.5 \%$ \\
Heroin Dependence & $24.1 \%$ & $40.6 \%$ \\
Marijuana Dependence & $27.6 \%$ & $12.1 \%$ \\
Hallucinogen Dependence & $10.3 \%$ & $5.3 \%$ \\
Polysubstance Use & $59.3 \%$ & $64.2 \%$ \\
\hline
\end{tabular}

${ }^{*}<.01$ 
Table 3

Differences in contract length between voluntary and court mandated participants.

\begin{tabular}{|c|c|c|}
\hline Contract Length & Voluntary $(n=65)$ & Court Mandated $(n=171)$ \\
\hline 30-Day ${ }^{* * * *}$ & $10.8 \%$ & $53.8 \%$ \\
\hline 60-Day ${ }^{* * * *}$ & $4.6 \%$ & $28.1 \%$ \\
\hline 90-Day & $13.8 \%$ & $9.9 \%$ \\
\hline 180-Day ${ }^{* * * * *}$ & $70.8 \%$ & $7.3 \%$ \\
\hline
\end{tabular}

*** $p<.001$ 


\section{Table 4}

Group differences between antisocial personality disorder (ASPD) and court mandated (CM) participants on demographics, substance dependence, and self report measures.

\begin{tabular}{|c|c|c|c|c|}
\hline & \multicolumn{2}{|c|}{ Voluntary Treatment Entry } & \multicolumn{2}{|c|}{ Court Mandated Treatment Entry } \\
\hline & $\begin{array}{c}\text { No ASPD } \\
(n=35)\end{array}$ & $\begin{array}{c}\text { ASPD } \\
(n=30)\end{array}$ & $\begin{array}{c}\text { No ASPD } \\
(n=62)\end{array}$ & $\begin{array}{c}\text { ASPD } \\
(n=109)\end{array}$ \\
\hline Age & $42.9(S D=8.7)$ & $39.4(S D=8.0)$ & $40.6(S D=10.4)$ & $40.9(S D=9.8)$ \\
\hline Income $(<20 k)$ & $51.4 \%$ a,b & $63.3 \%^{\mathrm{a}}$ & $54.1 \%{ }^{\mathbf{a}, \mathbf{b}}$ & $40.3 \%^{\mathbf{b}}$ \\
\hline \# of Previous Treatments & $2.97(S D=3.5)$ & $1.86(S D=1.46)$ & $2.10(S D=1.80)$ & $2.22(S D=2.11)$ \\
\hline Depressive Symptoms & $23.3(S D=12.9)$ & $24.9(S D=13.0)$ & $22.7(S D=10.7)$ & $22.3(S D=11.4)$ \\
\hline Alcohol Dependence & $34.3 \%$ & $56.7 \%{ }^{\mathrm{a}}$ & $26.6 \% \mathbf{b}$ & $32.3 \% \mathbf{b}$ \\
\hline Cocaine Dependence & $62.8 \%$ & $56.7 \%$ & $56.0 \%$ & $59.7 \%$ \\
\hline Heroin Dependence & $20.0 \%$ a & $33.3 \%$ & $40.3 \% \mathbf{b}$ & $48.4 \%$ b \\
\hline Marijuana Dependence & $11.4 \%$ & $30.0 \%$ a & $10.1 \% \mathbf{b}$ & $14.5 \%$ \\
\hline Hallucinogen Dependence & $5.7 \%$ & $3.3 \%$ & $6.4 \%$ & $6.5 \%$ \\
\hline Polysubstance Use & $50.0 \%$ a & $70.0 \%$ & $61.0 \%$ & $73.8 \%$ b \\
\hline
\end{tabular}

Differing subscripts indicate a significant group difference 


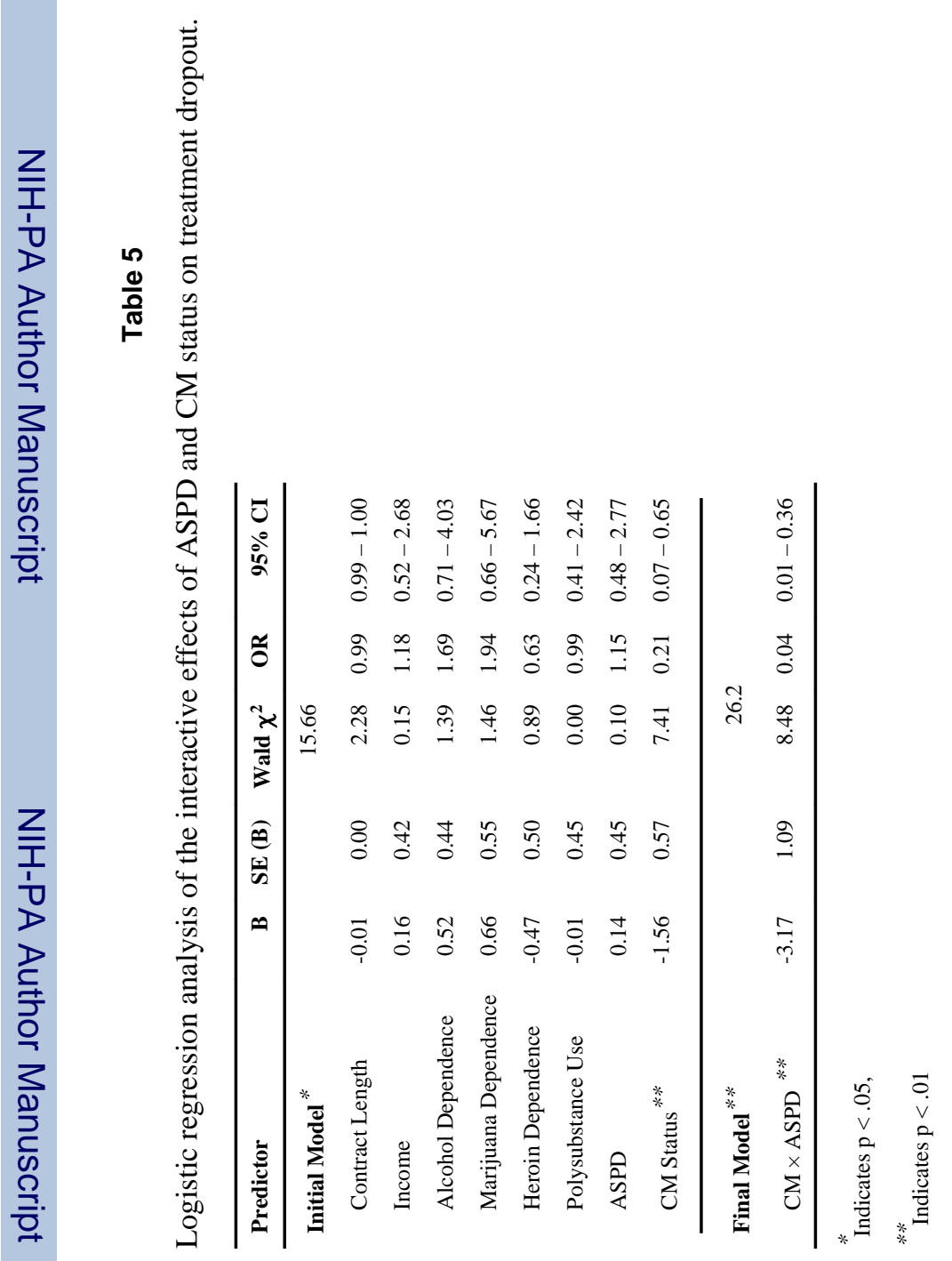

